\title{
BMJ Open Adolescents' experiences of being diagnosed with attention deficit hyperactivity disorder: a phenomenological study conducted in Sweden
}

Iwona Andersson Frondelius, ${ }^{1}$ Vania Ranjbar, ${ }^{2}$ Louise Danielsson ${ }^{2,3}$

To cite: Andersson Frondelius I, Ranjbar V, Danielsson L. Adolescents' experiences of being diagnosed with attention deficit hyperactivity disorder: a phenomenological study conducted in Sweden. BMJ Open 2019;9:e031570. doi:10.1136/ bmjopen-2019-031570

- Prepublication history for this paper is available online. To view these files, please visit the journal online (http://dx.doi org/10.1136/bmjopen-2019031570).

Received 09 May 2019 Revised 02 July 2019 Accepted 06 August 2019

Check for updates

(c) Author(s) (or their employer(s)) 2019. Re-use permitted under CC BY-NC. No commercial re-use. See rights and permissions. Published by BMJ.

${ }^{1}$ Department of Child and Adolescent Medicine, Angered Hospital, Gothenburg, Sweden

${ }^{2}$ Research Unit, Angered Hospital, Gothenburg, Sweden ${ }^{3}$ Department of Health and Rehabilitation, Institute of Neuroscience and Physiology, University of Gothenburg, Gothenburg, Sweden

Correspondence to Dr Louise Danielsson; louise.danielsson@gu.se

\section{ABSTRACT}

Objectives To explore adolescents' experiences of being diagnosed with Attention deficit hyperactivity disorder (ADHD).

Design Qualitative interview study, using a phenomenological framework and analysis.

Setting The children's clinic of a specialised out-care hospital located in a multicultural area of a Swedish city. Participants 13 adolescents, 7 boys and 6 girls between 14 and 19 years old, who had been diagnosed with ADHD. Results The participants' experience of being diagnosed with ADHD was interpreted as a process of understanding oneself as being different, for better or worse, like many others. The participants sought acceptance and a sense of normality, while developing an understanding of both the positive and the negative sides of their ADHD traits. These two sides of a coin were inter-related parts of themselves and were shared by many others, which increased their acceptance. Three themes described phases of the process: struggling with vulnerability, responding to a label and manoeuvring social life.

Conclusion The results add to previous research, illuminating that the adolescents tried to make sense of both the uniqueness and the vulnerability of the ADHD diagnosis. The findings can be useful for healthcare professionals, in reflecting on the complexity of ADHD and on the adolescents' expectations.

\section{INTRODUCTION}

Attention deficit hyperactivity disorder (ADHD) has a prevalence of $6 \%-11 \%$ in adolescents $^{1-3}$ and is defined as a number of characteristics involving attention and concentration difficulties, hyperactivity and lack of impulse control. ${ }^{4}$ To qualify for a diagnosis, the difficulties need to be present before the age of 12 , over a longer period of time and in at least two different contexts, causing significantly reduced function. ${ }^{4}$ Positive traits related to the condition, such as high energy levels, flexibility and creativity, are being increasingly highlighted in expert views of ADHD. ${ }^{5}$
Strengths and limitations of this study

- The interviewer had long clinical experience of assessing and treating adolescents with neuropsychiatric disorders, which enhanced sensitivity to the phenomenon.

- The reflective discussions and challenging of preconceptions and interpretations within the research group increased validity.

- The main limitation was the small sample, which hampered the variation of cultural backgrounds. A larger, more representative sample may have contributed with greater depth to the descriptions.

- Recall bias may have influenced the participants' accounts about experiences prediagnosis.

ADHD impacts significantly on various situations in the adolescent's life: at home, in school and with friends. ${ }^{6-10}$ Affected individuals often feel that they are less able to control their own actions and less capable of performing and socialising compared with their peers. ${ }^{78}$ The difficulties can lead to misunderstandings when the adolescent feels wrongly accused of something, or left out. ${ }^{10}$ Emotional dysregulation is prevalent, and proposed to be a core feature in ADHD. ${ }^{11}$ A reciprocal association between emotional regulation and attentional control has been suggested. ${ }^{12}$

Many adolescents with ADHD report feelings of low agency, ${ }^{13}$ victimisation and low health-related quality of life. ${ }^{14}$ While some studies suggest that adolescents with ADHD overestimate their competence compared with parent reports, ${ }^{15} 16$ others found that most adolescents with ADHD have an accurate and nuanced view of their functioning, ${ }^{17} 18$ suggesting that self-perception and functioning in ADHD is complex. Another viewpoint relate to psychological 
compensation, where the adolescent's problems are viewed as a mismatch between skills and environmental demands. ${ }^{19}$ Increasing effort, using other skills, or acquiring new skills, are ways to compensate, which can be adaptive or maladaptive. ${ }^{19}$

Adolescents with ADHD have different explanatory beliefs about the diagnosis: a personality trait, a physical disorder or a 'minor issue' in an otherwise ordinary life. ${ }^{20}$ Another study found that adolescents view ADHD as a disorder either related to performance, focusing on cognitive and educational achievements, or to conduct and social behaviour. ${ }^{21}{ }^{22}$ From the parents' perspective, the diagnosis can mean an impairment to achieving success, but it can also be a relief alleviating a sense of guilt. ${ }^{23}$ For adults diagnosed with ADHD, the diagnosis means both positive and negative traits, which are inseparable from their personality. ${ }^{24}$

A recently suggested theoretical framework for understanding adolescents' perceptions of ADHD is the Common Sense Model (CSM) ${ }^{25}{ }^{26}$ The model assumes that individuals actively form common sense beliefs about their illness in order to understand and cope with health problems. In short, when a person encounters a diagnosis, they develop interrelated cognitive and emotional representations of the illness, which guide their coping strategies. The representations include perceptions on: identity, cause, timeline, consequences, control/cure, emotional responses (towards the illness) and coherence (how much individuals believe they understand their illness). ${ }^{27}$ In ADHD research, much attention has been paid to the control/cure dimension, including the effectiveness of interventions, whereas other aspects, such as the timeline, consequences and coherence, deserve more attention. ${ }^{26}$

The number of children and adolescents seeking psychiatric care is growing ${ }^{2829}$ and many call for diagnostic assessments from healthcare. ${ }^{30}$ The conceptualisation of ADHD is evolving and there is a need to continue to illuminate young peoples' viewpoints. ${ }^{31}$ Culturally and socioeconomically diverse groups need to be included, since experiences may differ depending on social context. ${ }^{23}$ While previous research report experiences of ADHD-related behaviour and explanatory beliefs, there is a lack of studies addressing adolescents' experiences of the diagnostic process and what this process means to them. This knowledge could increase professionals' understanding about how to convey and educate about the diagnosis. Thus, the purpose of this study was to explore adolescents' experiences of being diagnosed with ADHD.

\section{METHODS}

\section{Methodology}

This study commits to what it means to adolescents to be diagnosed with ADHD. To capture this experience as it presents itself in adolescents' immediate, daily life-their life-world-a phenomenological approach inspired by Dahlberg et al. ${ }^{32-34}$ and Giorgi ${ }^{3536}$ was chosen.
Phenomenological research is concerned with the taken for granted, lived experiences and to reflect on them with curiosity. ${ }^{32}{ }^{35}$ This focus may elucidate unseen aspects of how these experiences appear and what they mean. Drawing on the works of Husser ${ }^{37}$ and MerleauPonty ${ }^{38}$ the meaning sought for is neither something objective, that we 'stumble on', ${ }^{39}$ nor is it the pure product of the researcher's interpretation. Rather, the research task commits to disclosing and clarify meaning as it is given. ${ }^{34}$ We were inspired by Dahlberg $e t a l^{3233}$ regarding the approach to objectivity, validity and generalisability.

Objectivity concerns the relation between the researcher and the phenomenon. ${ }^{33}$ Based on the life-world paradigm, researchers cannot be detached from the research subject since they have a certain understanding, known from experience or through established knowledge. The researchers need to be aware of this involvement, taking measures to hold back, or 'bridle', their preunderstanding of the phenomenon. This involves a scientific attitude characterised by careful self-reflection and openness. ${ }^{32} 33$ At the start of this study, we outlined our views and experiences of the phenomenon. We used reflexive journals, which were documents to write down memos and reflections during the analysis to help questioning and developing the interpretation.

Validity in phenomenological research connects to its meaning-oriented focus. ${ }^{32} 33$ Thus, the researcher needs to know the difference between content and meaning in the participants' narratives. Rather than reporting 'what' the adolescents said, we attempted to describe the meaning of these experiences from the adolescents' perspective.

While phenomenological accounts are from a limited number of subjects and might not be experienced by the entire population, the generated knowledge should be go beyond the individuals in the study. ${ }^{32}{ }^{33}$ We sought for empirically grounded descriptions, relevant to other adolescents in a similar context, which would illuminate both wholeness and specific parts of the experiences.

\section{Research team}

IAF is a child psychologist with more than 20 years' clinical experience in assessing and treating children and adolescents with ADHD, which would facilitate psychological sensitivity ${ }^{36}$ towards the phenomenon. VR is a psychologist/researcher experienced in qualitative research, but had not worked in clinical practice. LD has a background in mental health physiotherapy. She is a researcher and has conducted several qualitative studies based on phenomenological methodology. In this way, the research team provided different professional perspectives and expertise to the analysis in terms of clinical and methodological knowledge. The Standards for Reporting Qualitative Research guidelines were used. ${ }^{40}$

\section{Study setting}

The setting of this study was a specialised out-care hospital situated in the northeastern region of Gothenburg, the 
second largest city in Sweden. This particular region, which has a population of roughly 100000 inhabitants whereof around $50 \%$ are born outside Sweden ${ }^{41}$, is the hospital catchment area. In comparison with the county average, the prevalence of socio-economic disadvantage and high-risk lifestyles among children and adolescents are substantially higher and the inhabitants report high prevalence of physical and mental ill-health. ${ }^{42}$ The hospital aims to treat and prevent health problems in this area and to conduct research with the local inhabitants.

\section{Participants}

Inclusion criteria were: adolescents aged 13-19 years, diagnosed with ADHD and living in northeastern Gothenburg. Exclusion criteria were: not able to take part in a conversation in Swedish or having other established neuropsychiatric diagnoses.

Based on similar phenomenological studies, an estimated sample of 10-15 participants would be needed to reach a stable, yet nuanced, thematic structure in the analysis that would not change considerably with additional interviews. ${ }^{32} 43$ To gain variation of experiences and, thus, richness of data, a purposive sample ${ }^{32}$ with regard to different ages, sex and cultural backgrounds was sought for.

Initially, four adolescents were recruited from the children's clinic for the first interviews. Next, to reach a purposive sample, with a margin for non-responders, 25 adolescents from the children's clinic were selected from the clinic's registry and invited to participate. They received an invitation letter, followed up by a telephone call by the first author, IAF. This contact also had the purpose of building trust for the dialogue strived for in the subsequent interview. ${ }^{44}$ Participants and IAF were not to have had any previous clinical encounters.

Where potential participants were younger than 15 years old, their legal guardian was contacted first, to ensure that they had understood the information about the study and that their guardian supported the participation.

\section{Patient and public involvement}

There was no predefined patient or public involvement.

\section{Interviews}

The initial four interviews, conducted by IAF, were of a piloting character to try out interview questions and to start reflecting on the phenomenon. In an iterative manner, as qualitative data collection is often progressive ${ }^{45}$ these interviews helped the interviewer gain insights and improve the subsequent interviews. A semistructured interview guide was designed (table 1) and used for the remaining interviews, also conducted by IAF. The guide was based on open questions, and follow-up questions were used to help the participants elaborate on their descriptions to obtain rich data. ${ }^{3244}$ Examples of questions asked were 'Can you tell me about an ordinary day before you received your ADHD diagnosis?', 'How come you were assessed?", 'How was it for you to receive the diagnosis?'

All interviews took place in treatment rooms of the children's clinic. The adolescents could choose to have their parent present during the interview, but none did. The interviews lasted between 25 and 71 min, median $47 \mathrm{~min}$. They were audio-recorded and transcribed verbatim by IAF. Fictitious names, which were chosen by the participants themselves, were used to anonymise the transcripts.

Table 1 Interview guide to explore adolescents' experiences of being diagnosed with attention-deficit hyperactivity disorder (ADHD)

\begin{tabular}{|c|c|}
\hline Interview theme & Example of questions \\
\hline \multirow[t]{2}{*}{ Before the diagnosis } & $\begin{array}{l}\text { Can you tell me about an ordinary day before you received your ADHD diagnosis? How was it in } \\
\text { school, at home, with your friends? }\end{array}$ \\
\hline & What did you know about ADHD before you were diagnosed? \\
\hline \multirow[t]{3}{*}{ Assessment phase } & How come you were assessed? \\
\hline & Who initiated the assessment? \\
\hline & Tell me about the assessment, how was it for you? \\
\hline \multirow[t]{5}{*}{ Receiving the diagnosis } & How was it for you to receive the diagnosis? What did you feel? What did you think? \\
\hline & $\begin{array}{l}\text { Did you have concerns about the future, about what the diagnosis would mean? Do you have } \\
\text { concerns about the future now? }\end{array}$ \\
\hline & Did the diagnosis affect you in any way? \\
\hline & Who did you tell about being diagnosed? \\
\hline & $\begin{array}{l}\text { What would you like to tell professionals who assess and diagnose children, what should they think } \\
\text { about more? }\end{array}$ \\
\hline \multirow[t]{3}{*}{ Life after the diagnosis } & $\begin{array}{l}\text { How is your life today: with your family, friends, school? } \\
\text { Has the diagnosis made any difference for you? }\end{array}$ \\
\hline & What does the diagnosis mean to you? \\
\hline & Anything you want to add to the interview? \\
\hline
\end{tabular}




\section{Analysis}

The analysis followed the stepwise approach described by Giorgi ${ }^{35} 36$ and was conducted by IAF and LD. In step 1 , the textual data as a whole was read several times, to gain familiarity with the material and receive a first, general impression of the participants' experiences. Both researchers worked independently in this step. In step 2, IAF read the transcripts closely and marked each transition of meaning that might have any relevance to the research subject. Following this identification of parts (coded as meaning units phrased as close as possible to the participants' own words), step 3 involved grouping and transforming the meaning units into expressions that carry psychological value, close to the textual data. This phase was initially conducted by IAF, but later discussed and restructured on several occasions together with LD, with the authors trying out different variations and ways to capture the meaning of the participants' experiences. ${ }^{26}{ }^{32}$ Table 2 illustrates examples of this reflective process. Next (step 4), a tentative structure was developed to present the essential meaning (the common thread in the descriptions, the character of the phenomenon) and its particular thematic parts. This phase, of gradually refining the descriptions and use of quotations in the presentation, was a joint effort between the authors. Finally (step 5), the authors went back to the empirical data to compare the structure and presentation with the interviews as a whole. This phase also included rereading the interviews with the intention of exploring new aspects, and discussing with colleagues, thereby challenging and developing the interpretation.

\section{RESULTS}

Of the 25 invited adolescents, 10 agreed to take part in the study. Reasons for non-participation were as follows: parents declining participation $(n=3)$, the adolescent declining participation $(n=3)$, other neuropsychiatric disorder reported by the parent $(n=2)$, having moved from the area $(n=4)$ and not reachable $(n=3)$. One adolescent was later excluded when it became clear during the interview that he had severe psychiatric symptomatology that made it difficult to follow a conversation. Including the initial four from the pilot interviews, altogether 13 adolescents were interviewed, see table 3 for characteristics. All included participants were interviewed without the need for breaks or repeated interviews. However, one participant was fidgety and had some problems concentrating (had forgotten to take his medication), but wanted to continue the interview.

\section{Phenomenological analysis}

The participants' experiences of being diagnosed with ADHD was interpreted as a gradually developed understanding rather than a moment of realisation. The central meaning of this process was labelled being different, for better or worse, like many others, and is elaborated below. Three themes described different phases in this process; struggling with vulnerability (before the diagnosis); responding to a label (receiving the diagnosis); and manoeuvring social life (after the diagnosis). Fictitious names were used for the quotes included to illustrate meaning.

\section{Being different, for better or worse, like many others}

In the participants' experiences, being diagnosed essentially meant accommodating their differences in terms of ADHD-related traits. This meant seeing both the good and the bad of their condition as interrelated parts of themselves, like many others who shared these traits. Seeking acceptance and a sense of normality was important; however, the experience of differences compared with others remained. In their view, normality was related to self-respect and to identification with the ADHD population.

The participants tried to make sense, but also to make use, of their traits, which they both detested and yet came to like in what they called a 'love and hate relationship.' Being diagnosed with ADHD meant to recognise some traits as positive and even appreciate them as a gift, feeling special and unique compared with most people. Impulsivity and high energy caused restlessness in school, but facilitated endurance in some activities, such as sports. Intense emotions and expressiveness caused problems, but were also valued as inner richness, charisma and creativity. While developing an understanding of the complexity of ADHD and its commonness, the participants gained confidence and a sense of dignity. The diagnostic conceptualisation in itself was less significant, something they accepted with a shrug. The diagnosis was described as 'just a piece of paper' or 'a bracelet you just wear': it was the nuanced understanding of their traits that they were concerned with and that impacted on daily life.

\section{Struggling with vulnerability}

All participants described early, painful memories of being different and feeling frustrated and misunderstood, before being diagnosed. They described a chaotic daily life, with frequent rows with parents, friends and teachers. The outbursts felt unmanageable and shameful, but were also a way to let off steam:

I got so upset all the time. There was, like, irritation inside all the time. It felt great when I had an outburst, but at the same time it felt awful afterwards because I got so anxious, I couldn't remember what I'd said, and it's so hard when they get so sad, you know. (Anna)

At the same time, the participants liked being intense and energetic:

I had all this energy, I just can't sit still. When I was younger, I used to jump around all day long. I had so much more energy than the others, you know. When it was Saturday, they just wanted to chill, sit inside and play videogames. But I was like, running out to play and swim and go fishing. So it's a different thing. (Sebastian) 
Table 2 Example of the analysis resulting in the essence Being different, for better and worse, like many others

\begin{tabular}{|c|c|c|c|c|}
\hline Interview extract & Codes & $\begin{array}{l}\text { Reflection on the meaning of } \\
\text { extracts and codes }\end{array}$ & Theme & $\begin{array}{l}\text { Reflection on theme as part of the } \\
\text { essence }\end{array}$ \\
\hline $\begin{array}{l}\text { There were lots of problems and } \\
\text { fights in school. I cut classes and } \\
\text { did everything I wasn't supposed } \\
\text { to. } \\
\text { It was hard to realise that } \\
\text { everybody else could concentrate } \\
\text { and that I couldn't, and then it kind } \\
\text { of struck me, all these thoughts: } \\
\text { why can't I, what's wrong, really? }\end{array}$ & $\begin{array}{l}\text { Problems and fights. } \\
\text { Doing things you're not } \\
\text { supposed to. } \\
\text { Hard to realise that } \\
\text { everybody else is } \\
\text { capable. Doubting } \\
\text { oneself. }\end{array}$ & $\begin{array}{l}\text { Feeling different and wrong. } \\
\text { Trying to fit in but failing, leading } \\
\text { to frustration and feelings of } \\
\text { shame. A vulnerable position. } \\
\text { Do these experiences of being } \\
\text { different/vulnerable change in the } \\
\text { process of being diagnosed, and } \\
\text { if so, in what way? }\end{array}$ & $\begin{array}{l}\text { Struggling with } \\
\text { vulnerability }\end{array}$ & $\begin{array}{l}\text { Being different used to mean feeling } \\
\text { odd. When understanding more } \\
\text { about the pros and cons - how the } \\
\text { differences can be useful in life-they } \\
\text { start to accept differences more } \\
\text { although difficulties need to be dealt } \\
\text { with. }\end{array}$ \\
\hline $\begin{array}{l}\text { To know what it is, not having to } \\
\text { feel, like, What is this?, Why do I } \\
\text { feel this way ... why does it take } \\
\text { me so long to complete stuff?, } \\
\text { Why do I forget everything, where I } \\
\text { put my stuff, why do I have trouble } \\
\text { getting ready in the morning ...? } \\
\text { So you don't have to wonder so }\end{array}$ & $\begin{array}{l}\text { Knowing why. } \\
\text { Reasons for difficulties. }\end{array}$ & $\begin{array}{l}\text { Experiences of finding out a } \\
\text { reason for being different, a } \\
\text { name to put on the difficulties. } \\
\text { By getting a name, it seems } \\
\text { like something takes shape and } \\
\text { can be grasped, rather than } \\
\text { just vague frustration. It seems } \\
\text { mainly positive? Enhances their }\end{array}$ & $\begin{array}{l}\text { Responding to a } \\
\text { label }\end{array}$ & $\begin{array}{l}\text { The label helps explaining traits and } \\
\text { problems and can be a gateway to } \\
\text { assistance and medication, but also } \\
\text { has another, paradox meaning of } \\
\text { being exposed and feeling secluded. } \\
\text { The label builds expectations that are } \\
\text { rarely met. }\end{array}$ \\
\hline
\end{tabular}
much about these things.

I was happy about getting answers. That I actually had something and that there was a possibility to be calm and all that.

\section{it's much better that I tell them so that they know l've got extra energy, rather than just going there and they will think I'm mentally ill. \\ I feel like it's easier for me to hang out with people with $A D H D$ 'cause we share certain things. And I feel like ... if there are two persons with $A D H D$, you either love or hate each other. It's either too much or too little, you know, nobody's perfect, and there's a match 'cause you have the same mood, the same behaviour, almost the same thoughts, you know ... Yeah, I think that's good.}

It's a love-hate relationship for me, I guess. You stick out from the rest and that makes you special. But it's part of your personality, so it's a part of you. Even if it's hard, there are good sides to it, too.

You try to be proud of your ADHD so that you can live with it. It's ok if you don't like me, i have $A D H D$, I can be too much sometimes, kind of... Well it someone doesn't like it that you have $A D H D$, it's 'bye-bye' to them, you know, because it $[A D H D]$ is kind of a part of yourself.

... right now it's like having a bracelet on, for me. Yeah, something ordinary that's just there, something you just have. It's not uncommon that people have $A D H D$ now, I think.
Happy getting answers. Something definable.

\section{Better to tell so people} don't get the wrong idea.

They try to integrate what the have learnt about ADHD into the social contexts they are in. They also seem to "learning by doing" what strategies they can use to improve social situations and relationships.
Manoeuvring social The increased understanding about oneself, applied in daily life, changes self-perception and makes it less shameful to have ADHD. It is a part of oneself, but also part of many others, adding a sense of commonness and perhaps even normality.

ADHD, attention deficit hyperactivity disorder.

I feel everything so strongly, it's not just anger and sadness but it's joy and love and all that, too. I think it [ADHD] kind of intensifies everything and that's a good thing, too. (Anna)

\section{Reflections on the essence}

They have ambivalent feelings - a love-hate relationship towards their diagnosis. They feel special, for good and bad. And it is part of who they are. Seems linked to their process of growing up and making sense of themselves-about identity? Developing this dual meaning of being special and coming to terms with it seems essential!

They develop self-acceptance and sense of self-worth, along with the process of being diagnosed. That others have to accept that it is part of who they are and they cannot, and do not want to, change too much. The diagnosis becomes gradually embodied and integrated into life, and seem less thought about.

It is not controversial or preoccupying daily life. It is just something you 'have on'. Many others have it, it is like a brand. This attitude seems connected to that they learn to understand that so many share their traits. The metaphor of the bracelet connects to the dual meaning of being special, but it also suggests that ADHD is just there, not paying attention to it when absorbed in life's events

Like having a bracelet. Something ordinary. 
Table 3 Characteristics of the included participants

\begin{tabular}{|c|c|}
\hline Characteristics & $\begin{array}{l}\text { Participants } \\
(n)=13\end{array}$ \\
\hline \multicolumn{2}{|l|}{ Sex } \\
\hline Female & 6 \\
\hline Male & 7 \\
\hline \multicolumn{2}{|l|}{ Age } \\
\hline \multicolumn{2}{|l|}{ Median=16years } \\
\hline 14-16years & 7 \\
\hline 17-19years & 6 \\
\hline \multicolumn{2}{|l|}{ Age at ADHD diagnosis, years } \\
\hline \multicolumn{2}{|l|}{ Median $=11$ years } \\
\hline$<6$ (Preschool) & 0 \\
\hline 6-9 (Primary school) & 4 \\
\hline 10-12 (Middle school) & 5 \\
\hline 13-15 (Secondary school) & 4 \\
\hline \multicolumn{2}{|c|}{ Time since receiving the ADHD diagnosis } \\
\hline$<1$ year & 1 \\
\hline $1-3$ years & 4 \\
\hline$>3$ years & 8 \\
\hline Current ADHD medication & 11 \\
\hline Born in Sweden & 13 \\
\hline \multicolumn{2}{|l|}{ Cultural background } \\
\hline Swedish & 9 \\
\hline Lebanese & 1 \\
\hline Chilean & 2 \\
\hline Not specified & 1 \\
\hline
\end{tabular}

ADHD, attention deficit hyperactivity disorder.

Some participants described being picked on, being called a 'stupid DAMP kid' (During the late 1990s and early 2000s in Sweden, the term Deficits in Attention, Motor control and Perception (DAMP) was commonly used to describe ADHD symptoms. ${ }^{46}$ ) for example. The participants' knowledge of behaviour like their own came from 'DAMP kids' from their neighbourhood:

They were, like, the town's fools, you know. Everyone accused them of being annoying kids who never got things right ... so you only had that image that people with ADHD were a pain in the ass, really. (Anna)

With some exceptions, the participants said that the request for a diagnostic assessment had come from their parents. They suspected that the main reason behind the request for an assessment had been their social and emotional problems, rather than poor performance in school.

\section{Responding to a label}

This theme reflects the participants' experiences of the assessment and when they received the diagnosis. Most participants described that the assessment was quite fun, but it went on for too long. They recalled details disturbing their concentration in the test situation, such as a ticking clock on the wall. One girl described her anger and fear of the assessment when the diagnosis was conveyed, whereas the other participants described mixed emotions: surprise, worry, a sense of handicap and also a sense of relief. They did not understand what ADHD meant at the time, despite information they were given by professionals. They felt confused about the diagnosis, which meant that they belonged to a group they themselves looked down on: now they were 'one of them.' At the same time, it was comforting to know that their problems could be named and explained:

To know what it is, not having to feel, like, What is this?, Why do I feel this way ... why does it take me so long to complete stuff?, Why do I forget everything, where I put my stuff, why do I have trouble getting ready in the morning ...? So you don't have to wonder so much about these things. (Ines)

I was happy about getting answers. That I actually had something and that there was a possibility to be calm and all that. (Ricco)

The label provided a name for their condition, which made it easier to explain their difficulties. The participants described that the label 'ADHD' could mean different things, depending on the context. It could be used as a condescending stamp, but it was also a facilitator to professional help. With the diagnostic label as a door opener, the participants expected that their problems would be reduced or disappear. They hoped to finally calm down, to be able to focus and perform successfully:

My expectations were, like, I thought I would be the new Einstein as soon as I got medicine, but that didn't really come true [laughter]! (Victoria)

\section{Manoeuvring social life}

This theme reflects the participants' experiences of how the ADHD diagnosis affected their social life, after having received the diagnosis. Out of fear of being bullied, the participants were careful about whom to tell about their diagnosis:

I need to see if I can trust them. At first I didn't want to tell about having ADHD. No, because you can get bullied. And you don't want that so you got to trust people. (Elina)

Mainly, it was their teachers, best friend, or someone with similar problems that they confided in. One girl reported that when sharing with her best friend that she had ADHD, they had become closer. Parents, siblings, close friends and teachers could understand better and help to cope with difficult situations:

My two closest friends know [about the ADHD diagnosis] and they understand me better. I can tell them 
how I feel and they can say, "No, that's not how it is, you've got that wrong." When I'm about to take decisions too fast they make me reconsider. (Emma)

Another reason to tell others was the fear of being thought of as mentally ill. One boy said that even though he considered ADHD a handicap, he mentioned it to others so that they would not suspect any other, severe psychiatric disorders:

... 'cause it's much better that I tell them so that they know I've got extra energy, rather than just going there and they will think I'm mentally ill. (Sebastian)

Most participants were offered medication and some kind of adjustment in school, although support varied. Individual strategies were developed together with parents, teachers and friends. For example, one participant and his teacher came up with the strategy of going for a short walk when his frustration built up too much in the classroom. Taking part in smaller study groups was another strategy. In contrast, one boy described feeling humiliated by the school's policy to lock him out of the classroom when he had not taken his medication. Another participant described being called "dumb" by her teacher.

The participants often felt more comfortable with people who were like themselves:

I feel like it's easier for me to hang out with people with ADHD 'cause we share certain things. And I feel like ... if there are two persons with ADHD, you either love or hate each other. It's either too much or too little, you know, nobody's perfect, and there's a match 'cause you have the same mood, the same behaviour, almost the same thoughts, you know ... Yeah, I think that's good. (Emma)

For one participant, it first became clear what ADHD actually was when he studied together with other teenagers with ADHD. The participants looked up to older adolescents with ADHD or to celebrities who were open about ADHD. In this way, the diagnosis became a social attribute, increasing their sense of belonging.

My cousin, he's got ADHD medication, too. I think he told me, "I've got ADHD, too," and then I started to think that ADHD was cool, in a way. He was, like, 18 at the time. (Sebastian)

\section{DISCUSSION}

In this study, the adolescents' experiences of being diagnosed with ADHD essentially meant a process towards understanding their traits as both 'odd' and 'unique', and realising how common their problems were. The adolescents' understanding increased when they developed personal strategies and made sense of the diagnosis in the everyday interaction with friends, family and teachers.
The results suggested a dual meaning of being diagnosed with ADHD, in line with previous research highlighting both negative and positive sides of ADHD. ${ }^{32} 43$ Ghosh $e t a l^{23}$ described adult experiences of ADHD as a 'double-edged sword', where the negative sides had to be fixed. However, the adolescents in our study made no such claim. Rather, they described having to 'deal with the bad and the good'; it was all linked together as part of who they were. Similarly, in a study on bipolar disorder, ${ }^{37}$ participants portrayed their diagnosis as feeling gifted and simultaneously cursed, with the advantages of having the disorder inextricably linked to the difficulties. It may be useful for healthcare professionals to reflect on how their adolescent patients describe and integrate the positive and negative sides of their condition; how they learn to 'deal with the bad and the good'. Professionals could discuss with the adolescent, and their family, how to make the best use of their perceived positive traits, while managing the vulnerability connected to their negative symptoms.

The results connect to several dimensions in the CSM. ${ }^{25}$ The developed self-understanding described in the essential meaning relates to the coherence, consequence and time dimensions, proposed to need more attention in ADHD research. ${ }^{26}$ The findings illuminate both emotional and cognitive aspects, like the theme Responding to a label, which depicts the participants' mixed and sometimes strong emotions, but also their desire for logical explanations. The coherence dimension was also seen under the theme Manoeuvring social life, where grasping the diagnosis was strongly influenced by experiences in social interaction.

The adolescents in this study put substantial hope for change in being diagnosed. The diagnosis was expected to change their life, but their hope was not always fulfilled. Support in school, especially to have an adult who they felt seen by and trusted, was highly appreciated. However, not all were fortunate to have had positive experiences, in line with previous research. ${ }^{47-49}$ Based on the descriptions of painful disappointment regarding treatment effects and support, our results suggest that the adolescent's expectations on the consequences of being diagnosed may need increased recognition by healthcare. Since the adolescents' attitudes likely change, expectations could be reflected on at different time points: before the assessment, when the diagnosis is conveyed, and at follow-up visits.

The participants were inspired and made sense of their diagnosis in social interaction with other adolescents with ADHD that they knew or had heard of. This finding may be explored in future research by studying experiences and effects of 'peer-learning', for example, inviting older adolescents with ADHD to tell their stories to newly diagnosed adolescents.

Several participants described being proud of their diagnosis; identifying with and admiring certain people with ADHD. This finding may reflect the adolescents' desire to feel that they belong, ${ }^{50}$ but it may also reflect a change 
in the public awareness of ADHD, supported by recent autobiographies and books illustrating the advantages of ADHD. ${ }^{51}{ }^{52}$ In contrast, a recent review ${ }^{53}$ concludes that there is significant stigmatisation of adolescents and children with ADHD, characterised by a reluctance to socially interact with them. In our results, illuminated by Sebastian's quote under the theme of Manoeuvring social life, the participants informed people about their ADHD in order to avoid the risk of being thought of as mentally ill. This suggests that ADHD can be less stigmatising than other psychiatric disorders, also found by Walker et al, ${ }^{54}$ who compared stigmas surrounding ADHD and depression. Future studies may explore whether, and how, public and self-stigmas in ADHD are changing.

\section{Strengths and limitations}

The interviewer's long clinical experience with adolescents enhanced sensitivity to the phenomenon ${ }^{36}$ and facilitated an atmosphere where the participants could share their experiences. This was supported by the fact that only one of the participants expressed restlessness during the interview. However, while a semistructured interview guide was employed to ensure open questions, the interviewer's practice and habit of assessing adolescents might have affected the way she used follow-up questions.

Another strength was the analytic discussions (exemplified in table 2) and searching for descriptions that would challenge the tentative structure initially identified in the analysis. ${ }^{33}$ This way of critically looking at data is similar to the search for 'negative cases' in other types of qualitative research..$^{55}$ Nonetheless, the impact of researcher subjectivity cannot be ruled out. To enhance the reader's ability to judge the interpretation, the researchers' backgrounds were outlined.

The main limitation, potentially hampering trustworthiness, was a number of concerns related to the sample. Although data provided sufficiently rich descriptions to develop and justify the results, a larger sample may have contributed to greater depth in the interpretation. We provided detailed reasons for non-participation, but a more thorough analysis of reasons for declining participation would have been useful. Moreover, the sample was not sufficiently heterogeneous regarding cultural background. There were more female participants than expected considering that ADHD is two-three times more common in boys than in girls. ${ }^{1}$ The majority of the participants had been diagnosed more than 3 years ago, which may have influenced their ability to recall the time before and at the assessment. Thus, the rather long time span to adjust to the diagnosis could have contributed to less reports of problems and vulnerability. Other sampling strategies are suggested for future studies to involve culturally diverse groups, for example by contacting local community organisations. Snowball sampling, where a participant is asked if they know someone else who might be suitable for the study, would be another option, supported by our finding that the adolescents frequently socialise with others with ADHD.
Acknowledgements We would like to thank the adolescents in the study for sharing their experiences with us. We also want to thank Joel Danielsson and Yvonne Abedini for discussing the results and giving feedback on the manuscript.

Contributors IAF and VR designed and planned the study. IAF conducted the interviews. IAF and $L D$ analysed the data and drafted the manuscript, which were then revised and refined by all three authors (IAF, LD, VR).

Funding The authors have not declared a specific grant for this research from any funding agency in the public, commercial or not-for-profit sectors.

\section{Competing interests None declared.}

Patient consent for publication Not required.

Ethics approval The regional ethical review board, Gothenburg, Sweden, reference number $967-15$

Provenance and peer review Not commissioned; externally peer reviewed. Data availability statement Data are available upon reasonable request.

Open access This is an open access article distributed in accordance with the Creative Commons Attribution Non Commercial (CC BY-NC 4.0) license, which permits others to distribute, remix, adapt, build upon this work non-commercially, and license their derivative works on different terms, provided the original work is properly cited, appropriate credit is given, any changes made indicated, and the use is non-commercial. See: http://creativecommons.org/licenses/by-nc/4.0/.

\section{REFERENCES}

1. Erskine HE, Baxter AJ, Patton G, et al. The global coverage of prevalence data for mental disorders in children and adolescents. Epidemiol Psychiatr Sci 2017;26:395-402.

2. Thomas R, Sanders S, Doust J, et al. Prevalence of attention-deficit/ hyperactivity disorder: a systematic review and meta-analysis. Pediatrics 2015;135:e994-1001.

3. Vande Voort JL, He J-P, Jameson ND, et al. Impact of the DSM-5 attention-deficit/hyperactivity disorder age-of-onset criterion in the US adolescent population. J Am Acad Child Adolesc Psychiatry 2014;53:736-44.

4. American Psychiatric Association. Diagnostic and statistical manual of mental disorders. 5th ed. Washington, DC, 2013.

5. de Schipper E, Mahdi S, Coghill D, et al. Towards an ICF core set for ADHD: a worldwide expert survey on ability and disability. Eur Child Adolesc Psychiatry 2015;24:1509-21.

6. Cheung KKW, Wong ICK, Ip P, et al. Experiences of adolescents and young adults with ADHD in Hong Kong: treatment services and clinical management. BMC Psychiatry 2015;15.10.1186/s12888-0150478-x

7. Kendall J, Hatton D, Beckett A, et al. Children's accounts of attention-deficit/hyperactivity disorder. ANS Adv Nurs Sci 2003;26:114-30.

8. Shattell MM, Bartlett R, Rowe T. "I have always felt different": the experience of attention-deficit/hyperactivity disorder in childhood. $J$ Pediatr Nurs 2008;23:49-57.

9. Sikirica V, Flood E, Dietrich CN, et al. Unmet needs associated with attention-deficit/hyperactivity disorder in eight European countries as reported by caregivers and adolescents: results from qualitative research. Patient 2015;8:269-81.

10. Singh I, Kendall T, Taylor C, et al. Young People's Experience of ADHD and Stimulant Medication: A Qualitative Study for the NICE Guideline. Child Adolesc Ment Health 2010;15:186-92.

11. Faraone SV, Rostain AL, Blader J, et al. Practitioner Review: Emotional dysregulation in attention-deficit/hyperactivity disorder implications for clinical recognition and intervention. J Child Psychol Psychiatry 2019;60:133-50.

12. Karyotaki M, Drigas A, Skianis $C$. Attentional control and other executive functions. iJET 2017;12:219-33.

13. Wiener J, Daniels L. School experiences of adolescents with attention-deficit/hyperactivity disorder. J Learn Disabil 2016;49:567-81.

14. Dewey D, Volkovinskaia A. Health-Related quality of life and peer relationships in adolescents with developmental coordination disorder and attention-deficit-hyperactivity disorder. Dev Med Child Neurol 2018;60:711-7.

15. Volz-Sidiropoulou E, Boecker M, Gauggel S. The positive illusory bias in children and adolescents with ADHD: further evidence. J Atten Disord 2016;20:178-86.

16. Steward KA, Tan A, Delgaty L, et al. Self-Awareness of executive functioning deficits in adolescents with ADHD. J Atten Disord 2017;21:316-22. 
17. Bourchtein E, Langberg JM, Owens JS, et al. Is the positive illusory bias common in young adolescents with ADHD? A fresh look at prevalence and stability using latent profile and transition analyses. $J$ Abnorm Child Psychol 2017;45:1063-75.

18. Chan T, Martinussen R. Positive illusions? the accuracy of academic Self-Appraisals in adolescents with ADHD. J Pediatr Psychol 2016;41:799-809.

19. Merkt J, Reinelt T, Petermann F. A framework of psychological compensation in attention deficit hyperactivity disorder. Front Psychol 2015;6:1580.

20. Charach A, Yeung E, Volpe T, et al. Exploring stimulant treatment in ADHD: narratives of young adolescents and their parents. $B M C$ Psychiatry 2014;14:110.

21. Singh I. A disorder of anger and aggression: children's perspectives on attention deficit/hyperactivity disorder in the UK. Soc Sci Med 2011;73:889-96.

22. Singh I. Brain talk: power and negotiation in children's discourse about self, brain and behaviour. Sociol Health IIIn 2013;35:813-27.

23. Ghosh M, Fisher C, Preen DB, et al. "It has to be fixed": a qualitative inquiry into perceived ADHD behaviour among affected individuals and parents in Western Australia. BMC Health Serv Res 2016;16:141.

24. Hansson Halleröd SL, Anckarsäter H, Råstam M, et al. Experienced consequences of being diagnosed with ADHD as an adult - a qualitative study. BMC Psychiatry 2015;15:31.

25. Leventhal H, Phillips LA, Burns E. The Common-Sense model of self-regulation (CSM): a dynamic framework for understanding illness self-management. J Behav Med 2016;39:935-46.

26. Wong IYT, Hawes DJ, Clarke S, et al. Perceptions of ADHD among diagnosed children and their parents: a systematic review using the Common-Sense model of illness representations. Clin Child Fam Psychol Rev 2018;21:57-93.

27. Moss-Morris R, Weinman J, Petrie K, et al. The revised illness perception questionnaire (IPQ-R). Psychol Health 2002;17:1-16.

28. Bor W, Dean AJ, Najman J, et al. Are child and adolescent mental health problems increasing in the 21st century? A systematic review. Aust N Z J Psychiatry 2014;48:606-16.

29. Dalsgaard S, Nielsen HS, Simonsen M. Five-Fold increase in national prevalence rates of attention-deficit/hyperactivity disorder medications for children and adolescents with autism spectrum disorder, attention-deficit/hyperactivity disorder, and other psychiatric disorders: a Danish register-based study. J Child Adolesc Psychopharmacol 2013;23:432-9.

30. Atladottir HO, Gyllenberg D, Langridge A, et al. The increasing prevalence of reported diagnoses of childhood psychiatric disorders: a descriptive multinational comparison. Eur Child Adolesc Psychiatry 2015;24:173-83.

31. Whitaker R. Foreword. Int J Qual Stud Health Well-being 2017:12:1319588.

32. Dahlberg K, Dahlberg H, Nyström M. Reflective Lifeworld research. 2nd ed. Lund, Sweden: Studentlitteratur, 2008.

33. van Wijngaarden E, Meide Hvander, Dahlberg K. Researching health care as a meaningful practice: toward a Nondualistic view on evidence for qualitative research. Qual Health Res 2017;27:1738-47.

34. Dahlberg K. The essence of essences - the search for meaning structures in phenomenological analysis of lifeworld phenomena. Int J Qual Stud Health Well-being 2006;1:11-19.
35. Giorgi A. The phenomenological movement and research in the human sciences. Nurs Sci Q 2005;18:75-82.

36. Giorgi A. The descriptive phenomenological psychological method. Journal of Phenomenological Psychology 2016;47:3-12.

37. Husserl E. 1998. In: Ideas pertaining to a pure phenomenology and to a phenomenological philosophy. London, UK: Kluwer Academic Publication, 1913.

38. Merleau-Ponty M. Phenomenology of perception. London, UK: Routledge, 1995/1945.

39. Dahlberg KME, Dahlberg HK, vs D. Description vs. interpretation--a new understanding of an old dilemma in human science research. Nurs Philos 2004;5:268-73.

40. O'Brien BC, Harris IB, Beckman TJ, et al. Standards for reporting qualitative research: a synthesis of recommendations. Academic Medicine 2014:89:1245-51.

41. SAa S. Göteborgsbladet, SDN 132 Östra Göteborg. Gothenburg: The City Executive Office of Gothenburg, 2017b.

42. Götaland RV. Resultat från folkhälsoenkäten: Hälsa på lika villkor Västra Götaland 2011 [Results of the public health survey: Health on equal terms in Region Västra Götaland]. Gothenburg: Author; 2014

43. Guest $G$, Bunce A, Johnson L. How many interviews are enough?: an experiment with data saturation and variability. Field Methods 2006;18:59-82.

44. Kvale SB. Learning the craft of qualitative research interviewing. Thousand Oaks, California: SAGE Publications, Inc, 2009.

45. van Teijlingen E, Hundley V. The importance of pilot studies. Nursing Standard 2002;16:33-6.

46. Gillberg C. Deficits in attention, motor control, and perception: a brief review. Arch Dis Child 2003;88:904-10.

47. Gibbs K, Mercer KL, Carrington S. The schooling experience of adolescent boys with AD/HD: an Australian case study. Int J Dlisabil Dev Ed 2016;63:608-22.

48. Honkasilta J, Vehkakoski T, Vehmas S. 'The teacher almost made me cry' Narrative analysis of teachers' reactive classroom management strategies as reported by students diagnosed with ADHD. Teaching and Teacher Education 2016;55:100-9.

49. Kendall L. 'The teacher said I'm thick!' Experiences of children with Attention Deficit Hyperactivity Disorder within a school setting. Support for Learning 2016;31:122-37.

50. Morsink S, Sonuga-Barke E, Mies G, et al. What motivates individuals with ADHD? A qualitative analysis from the adolescent's point of view. Eur Child Adolesc Psychiatry 2017;26:923-32.

51. Hansen A. Fördel ADHD [Advantage ADHD]. Stockholm: Bonnier Fakta, 2017.

52. Frisk VG M. Min superkraft!: så har jag lärt mig att älska min struliga ADHD [My superpower!: how I came to love my messy ADHD]. Stockholm Bokförlaget Forum; 2017.

53. Lebowitz MS. Stigmatization of ADHD: a developmental review. $J$ Atten Disord 2016;20:199-205.

54. Walker JS, Coleman D, Lee J, et al. Children's stigmatization of childhood depression and ADHD: magnitude and demographic variation in a national sample. J Am Acad Child Adolesc Psychiatry 2008:47:912-20.

55. Morse JM, Barrett M, Mayan M, et al. Verification strategies for establishing reliability and validity in qualitative research. Int J Qual Methods 2002;1:13-22. 